\title{
ON THE SOLUTION OF ABEL INTEGRAL EQUATION BY THE METHOD OF FRACTIONAL INTEGRATION
}

(Presented by H. Keres)

In this paper a direct approach using fractional integration concept to solve the Abel integral equation for numerically defined functions $f(s)$ is developed. First, the integral values $\Phi(s)=\int_{0}^{s} \varphi(t) d t$ are determined keeping to the accuracy $O\left(l^{4}\right)$. Thereupon the values of the function sought for are found.

The Abel integral equation

$$
\frac{1}{\sqrt{\pi}} \int_{0}^{s} \frac{\varphi(t) d t}{\sqrt{s-t}}=f(s),
$$

where $f(s)$ is a given function defined on the positive halfaxis and $f(0)=0$ has the solution

$$
\varphi(s)=\frac{1}{\sqrt{\pi}} \int_{0}^{s} \frac{f^{\prime}(t) d t}{\sqrt{s-t}} .
$$

Difficulties arise, however, when $f(s)$ is not an analytically but experimentally obtained numerical function known only within certain error limits.

A direct approach in this case would be the use of the concept of fractional integration already familiar to Liouville and other analysts of the last century (nearly forgotten, however, by contemporary experts in integral equations) [1].

Defining the integral operator as a differential operator $D$ to the negative power -1 , we may express the integral of fractional order $\alpha$ $(\alpha>0)$ as $\left[{ }^{1-3}\right]$

$$
D-\alpha f(s)]_{0}^{s}=(\Gamma(\alpha))^{-1} \int_{0}^{s}(s-t)^{\alpha-1} f(t) d t .
$$

The Abel integral equation (1) may then be rewritten as $\left[{ }^{3}\right]$ :

$$
\left.D^{-1 / 2} \varphi(s)\right]_{0}^{s}=f(s) .
$$

Its solution is expressed by the corresponding derivative of the fractional order 


$$
\left.\varphi(s)=D^{1 / 2} f(s)\right]_{0}^{s}=D\left[D^{-1 / 2} f(s)\right]_{0}^{s}
$$

or

$$
\left.\Phi(s)=\int_{0}^{s} \varphi(t) d t=D^{-1 / 2 f}(s)\right]_{0}^{s} .
$$

If the values $f(s)$ include random experimental errors, the integral values $\Phi(s)$ are evidently smoother than the values $\varphi(s)$ themselves and it is preferable to find them first. The differential operator of an integer order $n$ is defined as the limit of a difference ratio to the corresponding power

$$
D^{n}=\lim _{l \rightarrow 0}\left(1-T^{-l}\right)^{n} / l^{n},
$$

where $T$ is the shift operator

$$
T^{-l} f(s)=f(s-l) .
$$

We assume that $f(s)$ (without errors) can be expanded into Taylor series. Then the shift operator is written by means of the $D$ symbol

$$
T^{-l} \equiv \mathrm{e}^{-l D}
$$

that reduces the definition (7) to the identity

$$
D^{n}=\lim _{l \rightarrow 0}\left(1-\mathrm{e}^{-l D}\right)^{n} / l^{n} .
$$

As a generalization of the definition (7) to the fractional order $\alpha(\alpha>0)$ we have

$$
D^{-\alpha}=\lim _{l \rightarrow 0}\left(1-T^{-l}\right)^{-\alpha / l^{-\alpha}}=\lim _{l \rightarrow 0}\left(1-\mathrm{e}^{-l D}\right)^{-\alpha / l^{-\alpha}} .
$$

Note that only the left shift and the left derivative are used due to the fact that the argument $s$ in our case is also the upper limit of integration.

Assuming $l$ to be smail, it is possible to use several approximate expressions for $D^{-1 / 2}$. In the error limits of the order $O\left(l^{2}\right)$

$$
\begin{gathered}
D^{-1,2} \approx D_{1}^{-1 / 2}=\left(\frac{4}{l} \operatorname{th} \frac{l D}{4}\right)^{-1 / 2}=\left(\frac{l}{4}\right)^{1 / 2}\left(\frac{1+\mathrm{e}^{-l D / 2}}{1-\mathrm{e}^{-l D / 2}}\right)^{1 / 2}= \\
=\frac{1+\mathrm{e}^{-l D / 2}}{2}\left(\frac{l}{1-\mathrm{e}^{-l D}}\right)^{1 / 2} .
\end{gathered}
$$

Doubling the interval length $l \rightarrow 2 l$, we have

$$
D_{2}^{-1 / 2}=\left(\frac{2}{l} \operatorname{th} \frac{l D}{2}\right)^{-1 / 2}=\frac{1+\mathrm{e}^{-l D}}{2}\left(\frac{2 l}{1-\mathrm{e}^{-2 l D}}\right)^{1 / 2} .
$$

According to the idea of Richardson $\left[{ }^{4}\right]$, we can now improve the approximation without any further diminishing of $l$ by a simple linear combination of $D_{1}$ and $D_{2}$

$$
D_{s}^{-1 / 2}=\left(4 D_{1}^{-1 / 2}-D_{2}^{-1 / 2}\right) / 3
$$

the error now being of the order $O\left(l^{-4}\right)$. This approximation for the 
ordinary integrals would give us the well-known Simpson integral formula.

Relying on this approximation, we need the expansions

$D_{1}^{-1 / 2}=\frac{1+\mathrm{e}^{-l D / 2}}{2}\left(\frac{l}{1-\mathrm{e}^{-l D}}\right)^{1 / 2}=\frac{1+\mathrm{e}^{-l D / 2}}{2} l 1 / 2 \sum_{0}^{N}(-)^{k}\left(\begin{array}{c}-1 / 2 \\ k\end{array}\right) \mathrm{e}^{-k l D}$

and

$D_{2}^{-1 / 2}=\frac{1+\mathrm{e}^{-l D}}{2}\left(\frac{2 l}{1-\mathrm{e}^{-2 l D}}\right)^{1 / 2}=\frac{1+\mathrm{e}^{-l D}}{2}(2 l)^{1 / 2} \sum_{0}^{N}(-)^{k}\left(\begin{array}{c}-1 / 2 \\ k\end{array}\right) \mathrm{e}^{-2 k l D}$,

where $\tilde{N}=\operatorname{int}(N / 2)$.

The values of the function at the midpoints of the intervals are also necessary. They can be found by interpolation using, for instance, the familiar Bessel four-point formula. In our symbolic notations it has the following form:

$$
\mathrm{e}^{-l D / 2} \approx 9\left(1+\mathrm{e}^{-l D}\right) / 16-\left(\mathrm{e}^{-2 l D}+\mathrm{e}^{l D}\right) / 16+O(l 4) .
$$

In all we now have computational formulae:

$$
\begin{gathered}
D_{1}^{-1 / 2}=\frac{25+9 \mathrm{e}^{-l D}-\mathrm{e}^{-2 l D}-\mathrm{e}^{l D}}{32} l^{1 / 2} \sum_{0}^{N}(-)^{k}\left(\begin{array}{c}
-1 / 2 \\
k
\end{array}\right) \mathrm{e}^{-k l D}, \\
D_{2}^{-1 / 2}=\frac{1+\mathrm{e}^{-l D}}{2}(2 l)^{1 / 2} \sum_{0}^{N}(-)^{k}\left(\begin{array}{c}
-1 / 2 \\
k
\end{array}\right) \mathrm{e}^{-2 k l D} .
\end{gathered}
$$

As $f(s)$ may be defined in our case only for the finite interval of abscissae and eventually cannot be extended to the right above a definite value of the argument, formula (14) does not permit to obtain necessary results, however.

Therefore it seems preferable to express $\mathrm{e}^{l D}$ by $\mathrm{e}^{-I D}, \mathrm{e}^{-2 l D}, \mathrm{e}^{-3 D}$ in the error limits $O\left(l^{4}\right)$ adopted by us. It is easy to see that within this accuracy the relation holds

$$
\mathrm{e}^{l D}=4-6 \mathrm{e}^{-l D}+4 \mathrm{e}^{-2 l D}-\mathrm{e}^{-3 l D}+O\left(l^{4}\right) .
$$

Substituting $\mathrm{e}^{I D}$ by this expression, we should have instead of (14) the following expansion for $D_{1}^{-1 / 2}$

$$
D_{1}^{-1 / 2}=\frac{21+15 \mathrm{e}^{-l D}-5 \mathrm{e}^{-2 l D}+\mathrm{e}^{-3 l D}}{32} l^{1 / 2} \sum_{0}^{N}(-)^{k}\left(\begin{array}{c}
-1 / 2 \\
k
\end{array}\right) \mathrm{e}^{-k l D} .
$$

Applying the formulae (6), (10), (15), and (17), the integral form of the solution of the Abel integral equation $\Phi(s)$ is readily found.

As $f(s)$ is an experimentally obtained function known only within certain error limits, the integral values $\Phi(s)$ will eventually need smoothing before the numerical differentiation $\left[{ }^{5}\right]$ to get the final solution $\varphi(s)$. We may apply here any integral sum formula that is accurate to the order $O\left(l^{4}\right)$. Such formulae are the Simpson integral formula and the Newton's favourite $3 / 8$ formula. For the interval $[0,3 l]$ they may be written as follows

$$
\Phi(2 l)-\Phi(0)=\int_{0}^{2 l} \varphi(s) d s=2 l\left(\varphi_{0}+4 \varphi_{1}+\varphi_{2}\right) / 6,
$$




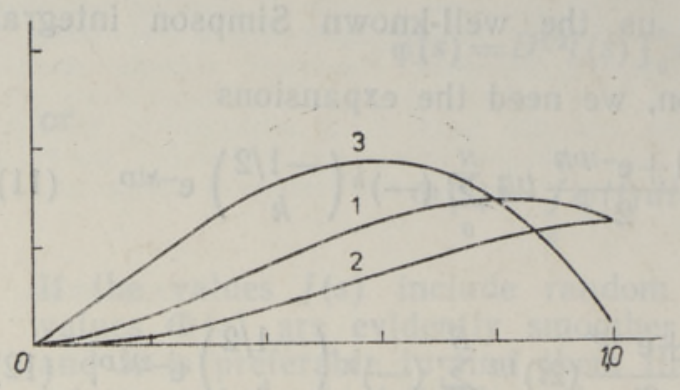

1 - Numerically defined initial function $f(s)$. 2 - Integral form of the solution $\Phi(s) .3$ - Solution $\varphi(s)$. Upon graphics exact solutions and computed ones coincide.

$$
\begin{gathered}
\Phi(3 l)-\Phi(l)=\int_{i}^{3 l} \varphi(s) d s=2 l\left(\varphi_{1}+4 \varphi_{2}+\varphi_{3}\right) / 6, \\
\Phi(3 l)-\Phi(0)=\int_{0}^{3 l} \varphi(s) d s=3 l\left(\varphi_{0}+3 \varphi_{1}+3 \varphi_{2}+\varphi_{3}\right) / 8 .
\end{gathered}
$$

This system of 3 equations has the following solution

$$
\begin{aligned}
& \varphi_{1}=\left(-\Phi_{3}+9 \Phi_{2}+9 \Phi_{1}-17 \Phi_{0}\right) / 18 l-\varphi_{0} / 3, \\
& \varphi_{2}=\left(2 \Phi_{3}+9 \Phi_{2}-18 \Phi_{1}+7 \Phi_{0}\right) / 9 l+\varphi_{0} / 3, \\
& \varphi_{3}=\left(13 \Phi_{3}-27 \Phi_{2}+27 \Phi_{1}-13 \Phi_{0}\right) / 6 l-\varphi_{0} .
\end{aligned}
$$

Here we have $\varphi_{0}=0=\Phi_{0}$. These formulae may be generalized to any triple of values $\varphi_{k+1}, \varphi_{k+2}, \varphi_{k+3}$, if $\varphi_{k}$ is known. Moreover, we need only the first of the formulae, i. e.

$$
\varphi_{k+1}=\left(-\Phi_{k+3}+9 \Phi_{k+2}+9 \Phi_{k+1}-17 \Phi_{k}\right) / 18 l-\varphi_{k} / 3 .
$$

This finishes the solution of the Abel integral equation (1).

Figure illustrates the application of the approximate formulae (10), (15), (17), (18), and (24) to the solution of the Abel integral equation

(1) in the case of a known exact solution $\varphi(s)$.

\section{REFERENCES}

1. Ш өстак Р. Я., В кн.: Исторнко-математические исследовання, вып. 5, М., Гостехиздат, 1952 , с. $167-230$.

2. Widder, D. V, An Introduction to Transform Theory, Academic Press, New YorkLondon, 1971, p. 113.

3. Курант Р., Курс дифференциального и интегрального исчисления, т. 2, М., «Наука», 1970, с. $362-364$.

4. М а рчук Г. И., Шайду ров В. В., Повышение точности решений разностных систем, М., «Наука», 1979 , с. 15.

5. Т ихонов А. Н., А рсен ин В. Я., Методы решения некорректных задач. М., «Наука», 1979 , с. $18-19$.

Academy of Sciences of the Estonian SSR,

Institute of Thermophysics and Electrophysics,

Received

Oct. 17,1980

\section{Institute of Physics}


A. PURGA, R. PREEM

\section{ABELI INTEGRAALVORRANDI LAHENDAMISEST MURDKORDSE INTEGRAALI MEETODIL}

Artiklis on kirjeldatud otsest meetodit Abeli integraalvõrrandi lahendamiseks juhul, kui lähtefunktsioon $f(s)$ on numbriliselt defineeritud. Esmalt määratakse otsitava funktsiooni $\varphi(s)$ integraal $\Phi(s)$ ja seejärel saadakse $\varphi(s)$ numbrilise integreerimise valemeid rakendades.

\section{А. ПУРГА, Р. ПРЕЭМ}

\section{РЕШЕНИЕ ИНТЕГРАЛЬНОГО УРАВНЕНИЯ АБЕЛЯ МЕТОДОМ ИНТЕГРИРОВАНИЯ ДРОБНОГО ПОРЯДКА}

Представлен метод решения интегрального уравнения Абеля

$$
\frac{1}{\sqrt{\pi}} \int_{0}^{s} \frac{\varphi(t) d t}{\sqrt{s-t}}=f(s)
$$

для случая,' когда искомая функция $f(s)$ задана в виде таблицы дискретных чисел (данных эксперимента). Решение проводится в два этапа. Сначала методом интегрирования дробного порядка определяется интегральная форма решения

$$
\Phi(s)=\int_{0}^{s} \varphi(t) d t,
$$

а затем путем использования формул численного интегрирования находится искомая функция $\varphi(s)$. 